\title{
Publisher Correction: Collapse of genetic division of labour and evolution of autonomy in pellicle biofilms
}

Anna Dragoš, Marivic Martin (1), Carolina Falcón Garcia @i, Lara Kricks, Patrick Pausch, Thomas Heimerl, Balázs Bálint (D), Gergely Maróti, Gert Bange, Daniel López, Oliver Lieleg and Ákos T. Kovács (D)

Correction to: Nature Microbiology https://doi.org/10.1038/s41564-018-0263-y, published online 8 October 2018.

In the version of this Article originally published, author Carolina Falcón Garcia's name was coded wrongly, resulting in it being incorrect when exported to citation databases. This has now been corrected, though no visible changes will be apparent.

Published online: 11 January 2019

https://doi.org/10.1038/s41564-018-0350-0 